\title{
INTRODUCTION
}

\section{5th Anniversary Issue of the Eastern Economic Journal}

\author{
Joyce P. Jacobsen and Gilbert L. Skillman
}

Eastern Economic Journal (2009) 35, 1. doi:10.1057/eej.2008.38

This issue of the Journal marks the beginning of our 35th year of publication as well as the 35th year of the Eastern Economic Association. It is also the beginning of our second year with our new publisher, Palgrave Macmillan. We are excited to have reached these milestones and hope that the Association and Journal will continue to serve both Association members and the broader economics community for many years to come.

In honor of this anniversary, we asked two former presidents of the Association to write short pieces reflecting on the changes since 1974 and the current state of the economics profession. Barbara Bergmann, our first president (1974) and one of the founders of the Association, who can always be counted on to be thoughtprovoking, contributes "The Economy and the Economics Profession - Both Need Work." David Colander, who served as president at the time of the Association's 20th anniversary (1994) and who continues to serve the Association and Journal as a member of our editorial board, follows with "In Praise of Modern Economics," which both reflects on Bergmann's piece and raises some additional considerations.

In this special issue we also include what we hope will become a regular Journal feature: the luncheon talk given by our president-elect at the previous year's Association meetings. Here we present, with minor edits by the author and added references, N. Greg Mankiw's well-received talk, "Smart Taxes: An Open Invitation to Join the Pigou Club," in which he argues for taxation of carbon emissions. 